\title{
The use of fluoride in infants and children
}

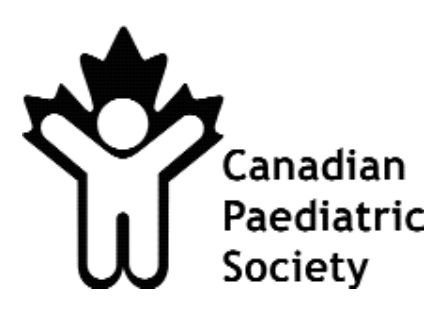

Français en page 579
$\mathrm{T}_{\mathrm{re}}^{\mathrm{h}}$ he introduction of fluoride to drinking water in 1958 resulted in a dramatic reduction of dental caries (1). Subsequently, fluoride supplements were advocated for children whose water was not fluoridated, and now almost all toothpaste contains fluoride. The result is that multiple sources of fluoride, such as fluoridated toothpastes, fluoride supplements (drops and lozenges) and naturally occurring fluoride, have contributed to an increase in the incidence of fluorosis. The challenge is to provide the right amount of fluoride in a reliable and safe manner. Fluoride has been found to be effective in preventing caries but there have been no controlled studies to evaluate the optimal dose.

The recommendations on fluoride use in a 1995 statement by the Canadian Paediatric Society (CPS) (2) differed substantially from those of the Canadian Dental Association (CDA). The position of the CDA (3) was that, apart from fluoride in water, the main source of fluoride should be fluoridated toothpaste, and that supplements should not be used in children younger than three years of age. The CPS position was that proper tooth brushing, especially in high risk populations, may be difficult to implement; that delaying supplementation until three years of age would result in higher caries rates; and that supplements should be started at six months of age (2). More recent studies of the actions of fluoride resulted in the modification of these two positions. The position outlined in the present statement follows the principles agreed on at the 1997 Canadian Consensus Conference on fluoride use (4).

\section{FLUOROSIS}

Dental fluorosis, a condition associated with abnormal enamel development, was first noted in communities with high levels of naturally occurring fluoride in the drinking water, but has since appeared in individuals ingesting fluoride from other sources.

This condition, occurring mainly in children younger than seven years of age, is associated with impaired biosynthesis of dental matrix. Manifestations can vary from minimal changes (Toxic Effect [TF] of 1), comprising $80 \%$ to $90 \%$ of the cases, and noted only by close dental examina- tion; to rarer, florid, unsightly mottling and pitting of the teeth, enamel striations, and in severe cases, 'snow-capped cusps' and chalky-white teeth (TF of 2 or more), which may be unsightly and require cosmetic treatment. Secondary teeth are at the greatest risk for fluorosis at 15 to 24 months of age (5).

The prevalence of fluorosis has increased since 1945 (6), paralleling the increase in possible sources of fluoride, including water, toothpaste, foods and drinks made with fluoridated water, and fluoride supplements such as drops, mouthwashes and lozenges. Fluorosis prevalence varies inversely with caries control. In a large study of 18,755 children by Heller et al (7), the sharpest decline in decayed, missing, filled surfaces occurred with increasing drinking water concentrations of fluoride from 0 to $0.7 \mathrm{ppm}$, with little additional benefit above this concentration. The prevalence of fluorosis increased with increasing water fluoride concentration, from $13.5 \%$ in children exposed to water containing less than $0.3 \mathrm{ppm}$ of fluoride to $41.4 \%$ when they were exposed to greater than $1.2 \mathrm{ppm}$. The use of supplements added to the effect and was associated with a further lowering of caries at the cost of increased fluorosis. A suitable trade-off between caries and fluorosis occurred at around $0.7 \mathrm{ppm}$ of fluoride (7). Other studies (8-10) have also found fluorosis prevalence of greater than $40 \%$ with increasing fluoride exposure, although only a small proportion of dental changes due to fluorosis are noticeable enough for treatment to be considered. A recent study of fluorosis among 2435 children aged seven to 13 years in Toronto, Ontario (11) found dental fluorosis of moderate degree (Tooth Surface Index of 2 - fluorosis of moderate severity) in $14 \%$ of seven-year-olds, $12.3 \%$ of 13 -year-olds and $13.2 \%$ of the two groups combined, a prevalence similar to most of the recent studies performed in Toronto.

\section{MECHANISM OF ACTION OF FLUORIDE}

Fluoride prevents caries mainly by its topical effect (12). Dental caries result when plaque, a sticky film of bacteria on the surface of the tooth, feeds on sugar and food residue to produce acid, which dissolves the surface of the tooth

Correspondence: Canadian Paediatric Society, 2204 Walkley Road, Suite 100, Ottawa, Ontario K1G 4G8. Telephone 613-526-9397,

fax 613-526-3332, Web sites www.cps.ca, www.caringforkids.cps.ca 


\begin{tabular}{l}
$\begin{array}{l}\text { TABLE 1 } \\
\text { Levels of evidence of the mechanisms of action of } \\
\text { fluoride in preventing tooth decay }\end{array}$ \\
$\begin{array}{l}\text { Level of } \\
\text { evidence (18) }\end{array}$ \\
\hline I \\
Description
\end{tabular}

(demineralization). Bathing the surface of the tooth with as little as $1 \mathrm{ppm}$ of fluoride causes a dramatic decrease in enamel solubility. Ingested fluoride, on the other hand, has little effect on caries, but contributes significantly to the development of fluorosis.

Enamel development is characterized by three stages.

- In the secretory stage, a protein matrix is laid down and mineral deposition begins.

- In the transition stage, protein is removed and replaced.

- In the maturation stage, protein is $95 \%$ replaced and mineralization is complete.

Fluoride delivered systemically to the tooth affects both the transition and maturation stages. Enamel development is most sensitive to systemic fluoride during the transition stage. The matrix becomes porous as fluoride and other ions accumulate. In the maturation stage, altered mineral depo- sition occurs. This effect of fluoride results in interference with crystal deposition, altered cell modulation and delayed maturation of bone.

Topical fluoride acts in three main ways to prevent dental caries (12).

- It inhibits plaque. Fluoride may kill or inhibit bacteria and makes them less able to produce acid from carbohydrates.

- It inhibits demineralization. Fluoride is incorporated into crystals on the tooth surface, making the surface more resistant to acid.

- It enhances remineralization of enamel. The process of demineralization and remineralization of enamel is constant. Fluoride increases the speed of this process and the incorporation of fluoride in the mineral makes it less soluble to acid.

\section{TOOTHPASTE}

Toothpaste is available with or without fluoride. Toothpaste tubes containing fluoride are now labeled and contain approximately $0.5 \mathrm{mg}$ fluoride per gram of toothpaste. Some tubes suggest covering the bristles with toothpaste. A 'peasized' portion weighs approximately $0.75 \mathrm{~g}$ and contains about $0.4 \mathrm{mg}$ of fluoride; a 'full cover' portion weighs approximately $2.25 \mathrm{~g}$ and contains about $1.0 \mathrm{mg}$ of fluoride. Thus, brushing twice a day would deliver 0.8 to $2.0 \mathrm{mg}$ of fluoride, depending on which regimen is used. If swallowed, the amount of fluoride could be excessive and could contribute to the development of fluorosis.

\section{UNDERLYING CONSIDERATIONS}

- The primary mechanism of the action of fluoride in preventing tooth decay is topical (evidence level II-3, recommendation B) $(11,13,14)$ (Table 1).

- Water fluoridation is an effective delivery method for topical fluoride (evidence level II-1, recommendation B) (1).

- Fluoridated toothpaste is an effective delivery method for topical fluoride (evidence level I, recommendation A) (15).

- The ingestion of more than the recommended daily dose of fluoride is associated with an increased risk of dental fluorosis (evidence level II-2, recommendation E) $(2,16)$.

- In the absence of adequate topical fluoride exposure (eg, fluoridated toothpaste or water), additional fluoride products may be provided in the form of drops, chewable tablets and lozenges. The effectiveness of these products in preventing dental caries is low in school-aged children (evidence level II-2, recommendation C) and has not been evaluated in infants and toddlers (evidence level II-3, recommendation C) (8). 
- Some individuals may be susceptible to 'carious challenge'. Because of either a genetic or an environmental predisposition to a high prevalence of caries (17-21), topical fluorides alone may be insufficient to prevent caries among these individuals (ie, additional fluoride may produce no net benefit and other measures such as antibacterial therapy and diet changes may be required) (evidence level II-3, recommendation C) (22).

\section{RECOMMENDATIONS}

There is no doubt that the use of fluoride decreases dental caries. On the other hand, it is clear that the ingestion of too much fluoride can result in varying degrees of fluorosis. Thus, in practice, the administration of fluoride should strike a balance between the two situations.

- The position outlined in the present statement follows the principles agreed to at the Canadian Consensus Conference on fluoride held in 1997 (4).

- Fluoride should continue to be added to municipal water supplies where natural concentrations are less than $0.3 \mathrm{ppm}$.

- A statement of fluoride concentration should continue to be printed on the toothpaste tube, and the amount in a 'pea-sized' portion of toothpaste should be indicated.

- Fluoride concentrations should be stated on any foods or drinks containing fluoride.

- Children should use only a 'pea-sized' amount of toothpaste, and be encouraged not to swallow the excess.
TABLE 2

Recommended supplemental fluoride concentrations for children

\begin{tabular}{lcc}
\hline Age of child & \multicolumn{2}{c}{$\begin{array}{c}\text { Fluoride concentration } \\
\mathbf{~} \mathbf{0 . 3} \mathbf{~ p p m}\end{array}$} \\
\hline 0 to 6 months & None & None \\
$>6$ months to 3 years & $0.25 \mathrm{mg} /$ day & None \\
$>3$ to 6 years & $0.5 \mathrm{mg} /$ day & None \\
$>6$ years & $1.00 \mathrm{mg} /$ day & None \\
\hline
\end{tabular}

- Because the action of fluoride is topical, no fluoride should be given before teeth have erupted.

- Supplemental fluoride should be administered (Table 2) only from the age of six months, and only if the following conditions prevail:

- the concentration of fluoride in drinking water is less than $0.3 \mathrm{ppm}$;

- the child does not brush his or her teeth (or have them brushed by a parent or guardian) at least twice a day; and

- if, in the judgment of a dentist or other health professional, the child is susceptible to high caries activity (family history, caries trends and patterns in communities or geographic areas).

- Supplemental fluoride should be given in preparations that maximize the topical effect, such as mouthwashes or lozenges. Drops, if used, should be diluted with water and squirted on the teeth.

\section{REFERENCES}

1. Newbrun E. Effectiveness of water fluoridation. J Pub Health Dent 1989;49:279-89.

2. Canadian Paediatric Society, Nutrition Committee. The use of fluorides in infants and children. Paediatr Child Health 1996;1:131-4.

3. Clark DC. Appropriate uses of fluoride in children: Guidelines from the Canadian Workshop on the Evaluation of Current Recommendations Concerning Fluorides. CMAJ 1993;59:272-9.

4. Limeback H, Ismail A, Banting D, et al. Canadian Consensus Conference on the appropriate use of fluoride supplements for the prevention of dental caries in children. J Can Dent Assoc 1998;64:636-9.

5. Evans RW, Darvell BW. Refining the estimate of the critical susceptibility to enamel fluorosis in human maxillary incisors. J Public Health Dent 1995;55:238-49.

6. Lewis DW, Banting DW. Water fluoridation, current effectiveness and dental fluorosis. Comm Dentist Oral Epidemiol 1994;22:153-8.

7. Heller KE, Ecklund SA, Burt BA. Dental caries and dental fluorosis at varying water fluoride. J Public Health Dent 1997;57:136-43.

8. Ismail AL. Fluoride supplements: Current effectiveness, side effects, and recommendations. Comm Dentistry Oral Epidem 1994;22:164-72.

9. Riordan PJ, Banks JA. Dental fluorosis and fluoride exposure in Western Australia. J Dent Res 1991;70:1022-8.

10. Ismail AL, Brodeur JM, Kavanagh M, et al. Prevalence of dental caries and dental fluorosis in students, 11-17 years of age, in fluorinated and non-fluorinated areas of Quebec. Caries Res 1990;24:290-7.

11. Leake J, Goettler F, Stahl-Quinlan B, Stewart H. Has the level of fluorosis among Toronto children changed? J Can Dent Assoc $2002 ; 68: 21-5$.

12. Shellis RP, Duckworth RM. Studies on the cariostatic mechanisms of fluoride. Int Dent J 1994;44(Suppl 1):263-73.

13. Featherstone JDB, Glena R, Shariati M, Shields CP. Dependence of in vitro demineralization of apatite and remineralization of dental enamel on fluoride concentration. J Dent Res 1990;69:620-5.

14. Thylstrup A. Clinical evidence of the role of pre-eruptive fluoride in caries prevention. J Dent Res 1990;60:742-50.

15. Clarkson JE, Ellwood RP. A comprehensive summary of fluoride dentifrices in clinical trials. Am J Dent 1993;6:59-106.

16. Osuji OO, Leake JL, Chipman ML, et al. Risk factors for dental fluorosis in a fluoridated community. J Dent Res 1988;67:1488-92.

17. Driscoll WS, Nowjack-Raymer R, Selwitz RH, et al. A comparison of the caries-preventing effects of fluoride mouth rinsing, fluoride tablets, and both procedures combined. J Public Health Dent 1992;52:111-6.

18. Canadian Task Force on the Periodic Health Examination. The periodic health examination: 2. 1987 update. CMAJ 1988;138:618-26.

19. Hassell TM, Harris EL. Genetic influences in caries and periodontal disease. Crit Rev Oral Biol Med 1995;6:319-42.

20. Ozawa Y, Chiba J, Sakamoto S. HLA class II alleles and salivary numbers of mutans streptococci and lactobacilli among young adults in Japan. Oral Microbiol Immunol 2001;16:353-7.

21. Hassell TM, Harris EL. Genetic influences in caries and periodontal diseases. Crit Rev Oral Biol Med 1995;6:319-42.

22. O'Sullivan EA, Curzon ME. Salivary factors affecting dental erosion in children. Caries Res 2000;34:82-7.

23. Seow WK. Prematurity as factor to enamel hypoplasia. Aust Dent J 1997;42:85-91. 


\section{NUTRITION COMMITTEE}

Members: Drs Margaret Boland, Children's Hospital of Eastern Ontario, Ottawa, Ontario (chair); Robert Issenman, Children's Hospital Hamilton HSC, Hamilton, Ontario (director responsible); Alexander Leung, Alberta Children's Hospital, Calgary, Alberta; Valérie Marchand, Hôpital Sainte-Justine, Montreal, Quebec; Anthony Otley, IWK Health Centre, Halifax, Nova Scotia

Consultants: Drs Claude Roy, Hôpital Sainte-Justine, Montreal, Quebec; Reginald Sauve, University of Calgary, Calgary, Alberta; Stanley Zlotkin, The Hospital for Sick Children, Toronto, Ontario

Liaisons: Ms Anne Kennedy, National Institute of Nutrition, Ottawa, Ontario; Marilyn Sanders, Breastfeeding Committee for Canada, Toronto, Ontario; Donna Secker, The Hospital for Sick Children, Toronto, Ontario; Rosemary Sloan, Population and Public Health Branch, Health Canada, Ottawa, Ontario; Christina Zehaluk, Health Products and Food Branch, Health Canada, Ottawa, Ontario

Principal author: Dr John Godel, Heriot Bay, British Columbia

The recommendations in this statement do not indicate an exclusive course of treatment or procedure to be followed. Variations, taking into account individual circumstances, may be appropriate.

Internet addresses are current at the time of publication. 